\title{
Identification and Characterization of an Exonic Duplication in $P A L B 2$ in a Man with Synchronous Breast and Prostate Cancer
}

\author{
Ahmed Bouras ${ }^{1, *(\mathbb{D})}$, Cyril Lafaye ${ }^{1}$, Melanie Leone ${ }^{1}$, Zine-Eddine Kherraf ${ }^{2,3}{ }^{(0)}$, Tanguy Martin-Denavit ${ }^{4,5}$, \\ Sandra Fert-Ferrer ${ }^{6}$, Alain Calender ${ }^{1}$ and Nadia Boutry-Kryza ${ }^{1}$
}

1 Genetic and Cancer Medical Laboratory HCL-CLB, Hospices Civils de Lyon, 69008 Lyon, France; cyril.lafaye@lyon.unicancer.fr (C.L.); melanie.leone@lyon.unicancer.fr (M.L.); alain.calender@chu-lyon.fr (A.C.); nadia.boutry-kryza@lyon.unicancer.fr (N.B.-K.)

2 Institute for Advanced Biosciences, University Grenoble Alpes, INSERM, CNRS, 38000 Grenoble, France; zekherraf@chu-grenoble.fr

3 UM GI-DPI, University Hospital Grenoble Alpes, 38000 Grenoble, France

4 Genetics Departement, Hospices Civils de Lyon, 69500 Bron, France; tanguy.martin-denavit@labo-alpigene.fr

5 Center for Medical Genetics, Alpigène, 69007 Lyon, France

6 Centre Hospitalier Métropole Savoie, Genetics Departement, 73011 Chambery, France; Sandra.Fert-Ferrer@ch-metropole-savoie.fr

* Correspondence: a.ahmed.bouras@gmail.com

\section{check for}

updates

Citation: Bouras, A.; Lafaye, C.;

Leone, M.; Kherraf, Z.-E.

Martin-Denavit, T.; Fert-Ferrer, S.; Calender, A.; Boutry-Kryza, N. Identification and Characterization of an Exonic Duplication in PALB2 in a Man with Synchronous Breast and Prostate Cancer. Int. J. Mol. Sci. 2022, 23, 667. https://doi.org/10.3390/ ijms23020667

Academic Editor: Andrea Nicolini

Received: 8 December 2021

Accepted: 6 January 2022

Published: 8 January 2022

Publisher's Note: MDPI stays neutral with regard to jurisdictional claims in published maps and institutional affiliations.

Copyright: (C) 2022 by the authors. Licensee MDPI, Basel, Switzerland. This article is an open access article distributed under the terms and conditions of the Creative Commons Attribution (CC BY) license (https:// creativecommons.org/licenses/by/ $4.0 /)$.

\begin{abstract}
PALB2 (partner and localizer of BRCA2), as indicated by its name, is a BRCA2-interacting protein that plays an important role in homologous recombination (HR) and DNA double-strand break (DSB) repair. While pathogenic variants of PALB2 have been well proven to confer an increased risk of breast cancer, data on its involvement in prostate cancer $(\operatorname{PrC})$ have not been clearly demonstrated. We investigated, using targeted next generation sequencing (NGS), a 59-year-old Caucasian man who developed synchronous breast and prostate cancers. This genetic investigation allowed to identify an intragenic germline heterozygous duplication in PALB2, implicating intronic repetitive sequences spanning exon 11 . This variant was confirmed by multiplex ligation probe amplification (MLPA), and genomic breakpoints have been identified and characterized at the nucleotide level (c.3114-811_3202-1756dup) using an approach based on walking PCR, long range PCR, and Sanger sequencing. RT-PCR using mRNA extracted from lymphocytes and followed by Sanger sequencing revealed a tandem duplication r.3114_3201dup; p.(Gly1068Glufs *14). This duplication results in the synthesis of a truncated, and most-likely, non-functional protein. These findings expand the phenotypic spectrum of PALB2 variants and may improve the yield of genetic diagnoses in this field.
\end{abstract}

Keywords: breast cancer; prostate cancer; PALB2; exon duplication

\section{Introduction}

Breast cancer remains the most frequent malignancy affecting women. This cancer is treated successfully in $~ 70-80 \%$ of cases diagnosed during the early stage [1]. Among all cases, $10 \%$ of patients seem to have a hereditary form of the disease (HBC). Genetic variants found in the breast cancer associated genes, BRCA1 (OMIM \#113705) and BRCA2 (OMIM \#612555), are considered as the most well-known breast cancer susceptibility factors. The lifetime cancer risk in carriers of pathogenic variants in these genes is estimated at $60-80 \%$ [2]. Therefore, routine genetic testing in HBC should focus on these two genes. Other novel candidate genes have subsequently been reported in this indication after negative testing for BRCA1-2 variants in several HBC cases such as CDH1, PALB2, PTEN, and TP53 $[3,4]$. Regarding this highly heterogeneous genetic basis, genetic screening of $\mathrm{HBC}$ is shifting from testing BRCA genes to broader panel testing.

Male breast cancer $(\mathrm{MBC})$ is a rare disease corresponding to less than $1 \%$ of breast cancers and about $0.5 \%$ of the malignancies in men in Western countries. The genetic 
basis underlying MBC predisposition is strong, and therefore, it is highly recommended to test affected men for high-penetrance germline pathogenic variants (PVs) in breast cancer susceptibility genes, regardless of family history of cancer [5].

PALB2 (partner and localizer of BRCA2, OMIM \#610355) is localized on chromosome 16 and encodes for a $B R C A 2$-interacting protein that serves as the molecular scaffold in the formation of the BRCA1-PALB2-BRCA2 complex. It is therefore crucial for homologous recombination and DNA double-strand break (DSB) repair [6]. As $B R C A 2$, germinal homozygous loss of function (LoF) variants of PALB2 lead also to Fanconi anemia [7,8], whereas heterozygous LoF variants have been associated with HBC and pancreatic cancer [9-11]. However, while pathogenic mutations in PALB2 have been recently associated with an increased risk of male breast cancer (MBC) [5], studies on its involvement in prostate cancer have given conflicting results. No previous study that we know has demonstrated statistically significant associations of PALB2 with PrC risk [11-14].

Here, we report the identification, using next-generation sequencing of a PALB2 complex variant (Alu-mediated exonic duplication) and its characterization and validation at the DNA and the RNA levels, of a man with synchronous prostate and breast cancer.

\section{Results}

\subsection{Case Presentation and NGS Analysis}

The proband-a 59-year-old man presented to the clinical genetics service at Hospices Civils de Lyon following the diagnosis of unilateral breast cancer (ER+, PR-, HER2-). A few months prior, the patient had undergone a prostatectomy following the discovery of prostate cancer. Post-operative staging and grading exposed a tumor without nodal metastasis and negative surgical margins (pT2c, N0, M0, R0) and a Gleason score of $3+4=7$ (Prognostic Grade Group 2).

In his family history, we find a nephew who died at the age of 25 from a cancer of unknown origin. The rest of the family history was not suggestive of an inherited cancer predisposition syndrome (Figure S1).

In order to identify any genetic variants that could explain the phenotype, the proband was analyzed using the CE-IVD Hereditary Cancer Solution (HCS) assay by SOPHiA Genetics. The results revealed PALB2 exon 11 duplication.

\subsection{MLPA Analysis and Breakpoint Characterization}

To confirm the identified duplication, MLPA was performed on the genomic DNA of the proband using the SALSA MLPA P260 PALB2-RAD50-RAD51C-RAD51D probe mix (MRC Holland, Amsterdam, The Netherlands). The results confirmed the presence of this germline duplication in the heterozygous state (Figure 1A).

To better characterize the PALB2 Exon 11 duplication, we confirmed this rearrangement by amplifying the genomic sequence spanning the exon 11 . This assay confirmed the presence of an approximately $2.5 \mathrm{~Kb}$ specific PCR product in the proband, which was absent in normal control samples. Sanger sequencing analysis of the PCR amplicon revealed a 47-nucleotide element overlapping the two introns, resulting in a duplicated region of $5134 \mathrm{bp}$ and allowing the accurate description of the duplication at DNA level (c.3114811_3202-1756dup) (Figure 1). According to the Repeat-Masker software analysis, two Alu elements oriented in the same direction are present in the regions flanking the genomic breakpoint, one in intron 10 (AluYa5) and the other in intron 11 (AluY). Sequence alignment showed that these two elements are highly homologous (Figure 2). 

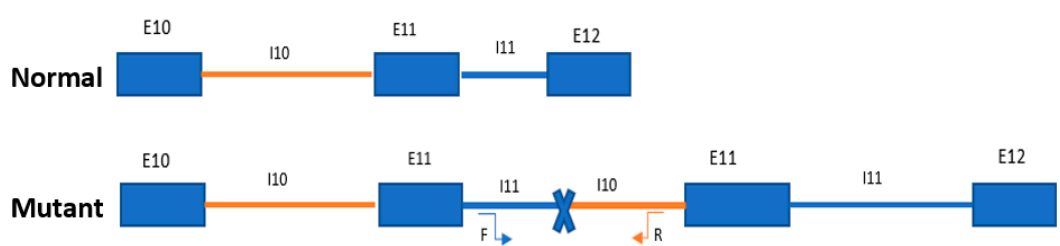

C

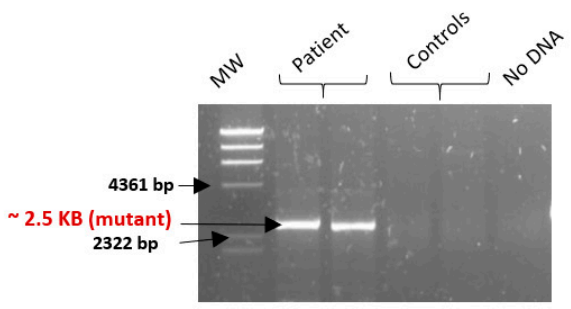

D

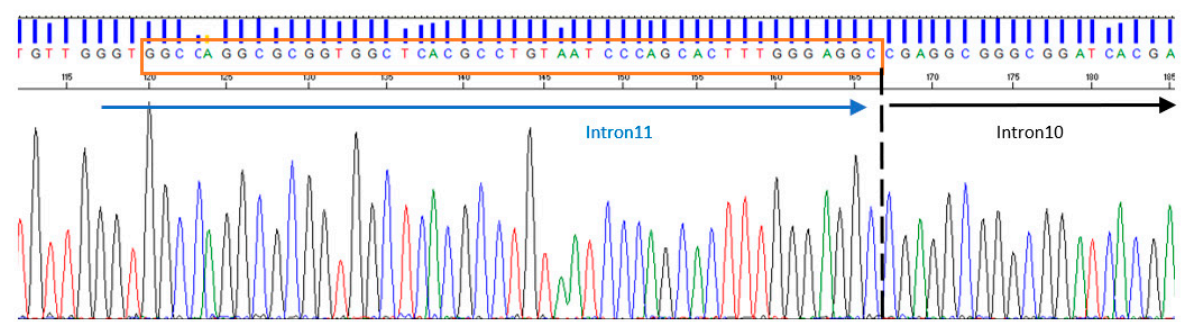

Figure 1. PALB2 Exon 11 duplication testing and breakpoint identification. (A) Schematic representation of the PALB2 normal and mutant alleles, with the duplicated region. The location and orientation of the primers used for specific duplication PCRs are indicated by vertical arrows. (B) PALB2 Exon 11 duplication confirmation by MLPA. (C) Long-range PCR. A specific band of approximately $2.5 \mathrm{~kb}$ was detected in the proband's blood DNA, absent in control samples. (D) Electropherogram showing the breakpoint sequence (forward). Tandem duplication site (TDS) is boxed in orange.

A

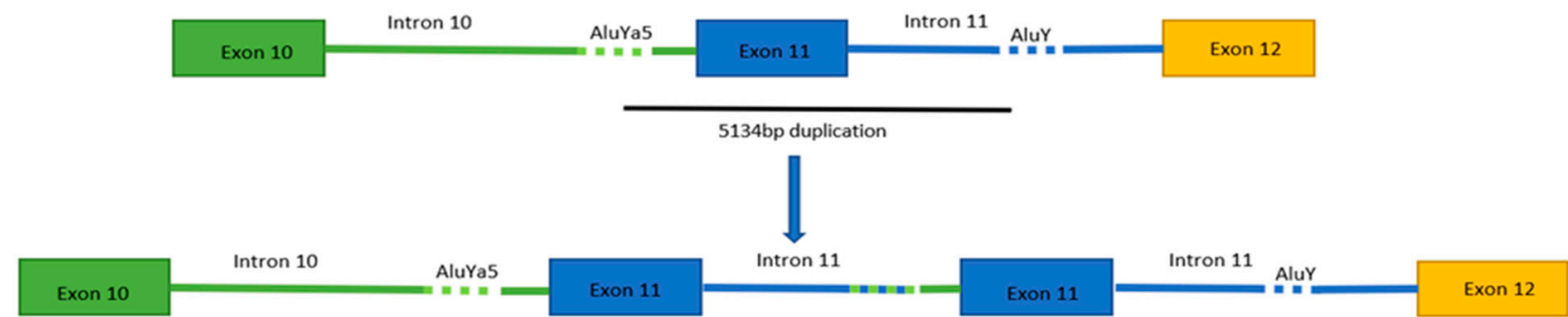

B

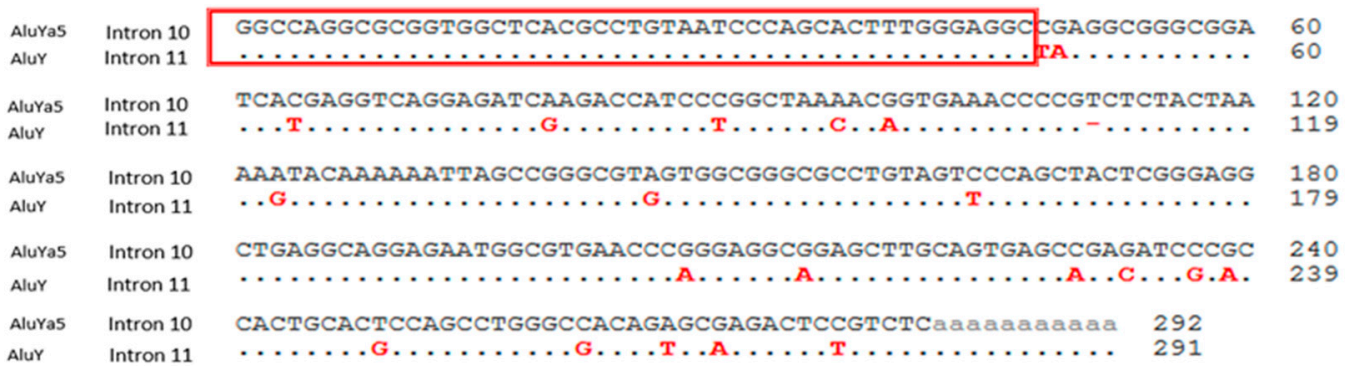

Figure 2. An Alu-mediated duplication mechanism appears to be responsible for exon 11 duplication. (A) Sequence analysis of the LR-PCR product allowed us to identify the duplication conjunctions that are located between c.3114-811 and 3202-1756. The location and orientation of the primers used for specific-duplication PCRs are indicated by vertical arrows. (B) Sequence alignment of the two Alu elements involved in this PALB2 rearrangement showing that these two elements are highly homologous. 


\subsection{RNA Analysis}

The impact of PALB2 exon 11 duplication at the RNA level was evaluated by performing an RT-PCR on the proband's RNA by a single primer set to amplify the PALB2 cDNA sequence flanking exon 11 . We obtained two bands with different sizes after gel electrophoresis: a band at the expected size $(388 \mathrm{bp})$ of the amplified fragment from the wild-type allele and a long band of about $474 \mathrm{bp}$. Sanger sequencing analysis of the long fragment evidenced that the duplication is in tandem. This abnormal transcript leads to a frameshift and a premature stop codon, thus confirming the deleterious impact of the identified variants on the protein functional structure (Figure 3).
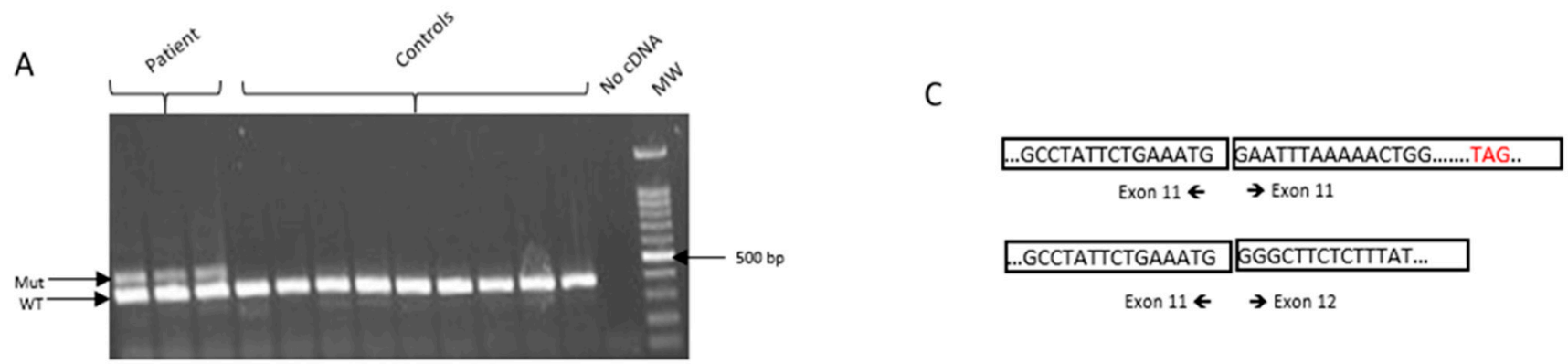

B

T A G

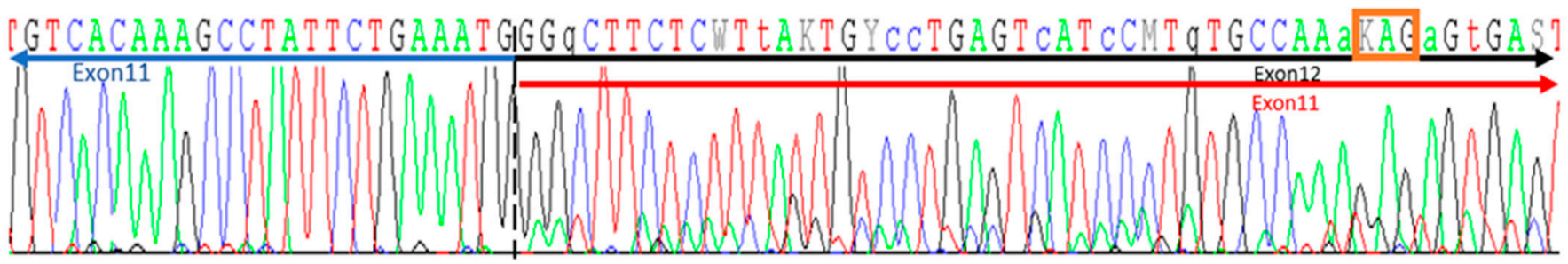

Figure 3. PALB2 Exon 11 duplication disrupts normal splicing and leads to frameshift. (A) Agarose gel electrophoresis of the RT-PCR performed with mRNA obtained from the patient and non-carrier controls. An extra band was observed in the patient of about $474 \mathrm{bp}$, while only the wild-type band was observed in controls (388 bp). (B) Sanger sequencing of the two alleles of RT-PCR product of the sample from proband: the insertion leads to a new stop codon as indicated by the red box. (C) Schematic representation of the two transcripts observed in the proband sample.

\section{Discussion}

In the present study, we identified, by NGS, an exonic duplication occurring in the PALB2 gene in a man who developed synchronous breast and prostate cancers at 59 . The identified duplication was verified and validated by MLPA, and the breakpoints flanking the duplicated sequence were characterized at the nucleotide level by LR-PCR and Sanger sequencing (c.3114-811_3202-1756dup). A further characterization of this variant at the RNA level demonstrated the production of an abnormal transcript leading to the translation of a truncated protein (r.3114_3201dup; p.(Gly1068Glufs *14)).

Until now, the association between BRCA1/2 pathogenic variants and female/male breast cancer incidence, as well as ovarian and pancreatic cancer, has been widely reported. In addition to these genes, genetic alterations involving PALB2 have been also described as implicated in these cancers. However, PALB2 pathogenic mutations have not been extensively studied in patients with prostate cancer. In 2020, Yang et al. reported the results of a multicentric study conducted on 523 families and did not reveal any correlation between PALB2 germline pathogenic variants and increased risk for prostate cancer [14]. In contrast, Wokolorczyk et al. have shown in 2021 that the two founder mutations of PALB2 
in the Polish population (c.509_510delGA and c.172_175delTTGT), which represent $~ 80 \%$ of all PALB2 mutations, were commonly diagnosed within aggressive cancers of a high Gleason score (8-10) rather than middle Gleason score tumors (7) [15]. Other studies have established the occurrence of germline PALB2 mutations in prostate cancer as well as the sensitivity of other PALB2-deficient tumor entities to Poly(ADP-ribose)polymerase (PARP) inhibition [16-18]. PARP inhibitors are oral agents that exert their activity through the concept of synthetic lethality [19]. At present, two PARP inhibitors are approved by the FDA for use in Castration-Resistant Prostate Cancer (Opalarib and Rucaparib) [20].

Usually, the genomic consequences of large duplications are difficult to infer without analyzing the RNA or determining the exact breakpoints. Thus, determining the genomic breakpoints of these large genomic rearrangements (LGRs) is essential to interpret their effect on genes and their correlation with phenotypes. In addition, analysis of genomic breakpoints can help characterize the molecular mechanisms behind these rearrangements. Two main mechanisms are involved: homologous (HR) and non-homologous recombination (NHR). The presence of highly homologous sequences in genomic breakpoints generally indicates $\mathrm{HR}$, while the absence of sequence homology indicates a non-homologous mechanism [21]. To date, most of the reported pathogenic PALB2 variants are spliced and nonsense/indel variants. Several pathogenic large duplications have been reported, such as exons 9-11 duplication [22] and exon 13 duplication [23]. Richardson et al. reported PALB2 exon 11 duplication in his study about large duplications in breast cancer predisposition genes using a DNA breakpoint assay based on a custom NGS method. For PALB2 EX11dup, two sets of breakpoints were identified in several families. One family had breakpoints in the AluYa5 and AluY element (5': intron 10 and $3^{\prime}$ : intron 11, respectively), while another proband had both breakpoints upstream of each of those breakpoints in the AluSz and AluSx element, respectively. In accordance with our study, we found the same reported first set of breakpoints (c.3114-811_3202-1756dup) that we have validated at both the DNA and RNA levels in an independent study. As previously reported in other studies that Alu-mediated HR is a frequent mechanism underlying PALB2 large duplications [23,24].

In addition to the previous study conducted by Richardson et al. [24], this LGR with the same breakpoint was also identified in another unrelated family in our laboratory. The family had a female proband with a triple negative (TNG) breast cancer diagnosed with brain metastases at 36 . The proband had, in her antecedent, a melanoma diagnosed at the age of 22 years (Figure S2). By integrating the genetic information and the family history, in addition to molecular arguments, we could conclude that this LGR is pathogenic and recurrent in the region.

Besides improvements of genetic diagnosis for these two types of cancer, these findings may additionally have therapeutic implications. There is strong evidence that (likely) pathogenic PALB2 variants confer breast cancer risks that are considered as moderate to high. Therefore, multidisciplinary committees should advise a close surveillance and discuss the indication of a contralateral prophylactic mastectomy in these patients [25]. Finally, our patient was treated with a total mastectomy of the right breast followed by chemotherapy, adjuvant radiotherapy, and hormone therapy (Tamoxifen). The patient was not receptive to the contralateral prophylactic mastectomy.

Overall, we characterized, in a man with a synchronous prostate and breast cancer at both the DNA and RNA levels, a tandem and direct intragenic duplication in PALB2, which likely occurred by Alu-mediated homologous recombination. These findings expand the phenotypic spectrum of PALB2-associated cancer and may improve the mutation-based screening and genetic diagnosis of breast cancer.

\section{Materials and Methods}

\subsection{Subjects and DNA Extraction}

The patient, at 59 years old, addressed by department of clinical genetics of the university hospital of Lyon (Hospices civils de Lyon), Lyon, France. 
Total genomic DNA was extracted from blood samples using the automated procedure implemented on the STARlet platform (Hamilton Company, Reno, NV, USA).

\subsection{NGS Analysis and MLPA Confirmation}

All subjects in this study were tested after giving informed consent after genetic counseling.

The DNA of the proband was processed by the commercial Hereditary Cancer Solution (HCS) kit (SOPHiA GENETICS, Saint-Sulpice, Switzerland) as described previously [26]. A total of 26 genes were analyzed using the NGS method (ATM, APC, BARD1, BRCA1, BRCA2, BRIP1, CDH1, CHEK2, EPCAM (large rearrangement only), FAM175A, MLH1, MRE11A, MSH2, MSH6, MUTYH, NBN, PALB2, PIK3CA, PMS2, PTEN, RAD50, RAD51C, RAD51D, STK11, TP53, and XRCC2). Duplication of PALB2 exon 11 was confirmed by multiplex ligation-dependent probe amplification (MLPA) using the SALSA MLPA P260 PALB2-RAD50-RAD51C-RAD51D probe mix (MRC Holland, Amsterdam, The Netherlands) according to the manufacturer's instructions.

\subsection{Long-Range PCR and Breakpoint Determination}

The characterization of the genomic breakpoint of the PALB2 exon 11 duplication was based on the hypothesis that this LGR occurred in tandem and in direct orientation.

Since then, an LR-PCR has been performed using specific duplicating primers, in which the forward primer is located at the beginning intron 11 of PALB2 and the reverse primer at the end of intron 10 (Figure 1A). Subsequently, to narrow the distance to the duplication breakpoint, a primer walking strategy was used with several forward primers located at intron 11 and reverse primers at intron 10. All PCR reactions were performed using Platinum ${ }^{\mathrm{TM}}$ SuperFi ${ }^{\mathrm{TM}}$ PCR Master Mix (Thermo Fisher Scientific, Invitrogen, Villebon sur Yvette, France) according to the manufacturer's instructions. Amplified products were sequenced on a 3730 Genetic Analyzer using Big Dye Terminator Chemistry (Thermo Fisher Scientific, Waltham, MA, USA) according to the manufacturer's recommendations. In each amplification, two normal samples were used to control PCR specificity. PCR conditions were denatured at $98^{\circ} \mathrm{C}$ for $5 \mathrm{~min}$ for 35 cycles (denaturation $98{ }^{\circ} \mathrm{C}$ for $30 \mathrm{~s}$, annealing $60{ }^{\circ} \mathrm{C}$ for $10 \mathrm{~s}$, extension $72{ }^{\circ} \mathrm{C}$ for $4 \mathrm{~min}$ ), followed by final extension at $72{ }^{\circ} \mathrm{C}$ for $5 \mathrm{~min}$.

The duplication junction was amplified with a specific primer forward F-11 AGACCGCATCTTTCCCTAGC located in intron 11 and reverse R10-ATAAAGTTTGTTGGAATCACT TCCC located in intron 10, followed by direct sequencing to confirm the breakpoint. Sequencing reactions were performed with the BigDye Terminator v.3.1 cycle sequencing kit (Applied Biosystems, Waltham, MA, USA) on an ABI 3730XL sequencer according to the manufacturer's instructions. The sequences were aligned against the wild-type PALB2 nucleotide sequence (NM_024675; transcript ID).

\subsection{RNA Analysis}

RNA from the proband was extracted from the PAXgene Blood RNA Kit (PreAnalytiX, Qiagen, Valencia, CA, USA) and used for cDNA synthesis (Superscript III FirstStrand Synthesis SuperMix, Invitrogen, Villebon sur Yvette, France). PCR was performed using a Platinum ${ }^{\mathrm{TM}}$ Taq DNA Polymerase (Thermo Fisher Scientific, Invitrogen, Villebon sur Yvette, France) and primers covering a region between exon 9 and 12 (forward: GTTAGTAGCAGTGGGACCCT-3' and reverse: 5' -TCACAATGAGCTGAAACACA $3^{\prime}$ ) with the following reaction conditions: $95^{\circ} \mathrm{C}$ for $4 \mathrm{~min}$, initial denaturation, 14 cycles of $1 \mathrm{~min}$ at $95^{\circ} \mathrm{C}, 1 \mathrm{~min}$ at $62^{\circ} \mathrm{C}$ with an increase of $0.5^{\circ} \mathrm{C}$ every PCR cycle, $2 \mathrm{~min}$ at $72{ }^{\circ} \mathrm{C}$, 25 cycles of $1 \mathrm{~min}$ at $95{ }^{\circ} \mathrm{C}, 1 \mathrm{~min}$ at $55^{\circ} \mathrm{C}, 2 \mathrm{~min}$ at $72{ }^{\circ} \mathrm{C}$ followed by $7 \mathrm{~min}$ at $72{ }^{\circ} \mathrm{C}$ for subsequent Sanger sequencing. Control RNA was extracted from HBC patients without the PALB2 exon 11 duplication. The detailed protocol is available on request. The recommendations of the French Unicancer genetic Group were followed for the interpretation of the results [27]. 
Supplementary Materials: The following are available online at https:/ /www.mdpi.com/article/ $10.3390 /$ ijms23020667/s1.

Author Contributions: Conceptualization, A.B.; methodology, A.B. and N.B.-K.; writing-original draft preparation, A.B.; performance of the experiments, M.L. and C.L.; writing-review and editing, A.B., A.C., C.L., M.L., S.F.-F., T.M.-D., Z.-E.K. and N.B.-K. All authors have read and agreed to the published version of the manuscript.

Funding: This research received no external funding.

Institutional Review Board Statement: Ethical review and approval were waived for this work by following the guidelines of our Regional Ethics Committee, which reports that the evaluation of a single case report or case series (up to 5 cases) whose sole purpose is reporting, i.e., the purpose of which is to describe some unusual or new cases, is not within the remit of the Ethics Committee.

Informed Consent Statement: Informed consent was obtained from all subjects involved in the study.

Data Availability Statement: The data presented in this study are available on request from the corresponding author. The data are not publicly available due to restrictions of patient privacy.

Conflicts of Interest: The authors declare that they have no conflict of interest.

\section{References}

1. Harbeck, N.; Penault-Llorca, F.; Cortes, J.; Gnant, M.; Houssami, N.; Poortmans, P.; Ruddy, K.; Tsang, J.; Cardoso, F. Breast Cancer. Nat. Rev. Dis. Primer 2019, 5, 66. [CrossRef]

2. Kobayashi, H.; Ohno, S.; Sasaki, Y.; Matsuura, M. Hereditary Breast and Ovarian Cancer Susceptibility Genes (Review). Oncol. Rep. 2013, 30, 1019-1029. [CrossRef]

3. Moretta, J.; Berthet, P.; Bonadona, V.; Caron, O.; Cohen-Haguenauer, O.; Colas, C.; Corsini, C.; Cusin, V.; De Pauw, A.; Delnatte, C.; et al. The French Genetic and Cancer Consortium guidelines for multigene panel analysis in hereditary breast and ovarian cancer predisposition. Bull. Cancer 2018, 105, 907-917. [CrossRef]

4. Cobain, E.F.; Milliron, K.J.; Merajver, S.D. Updates on Breast Cancer Genetics: Clinical Implications of Detecting Syndromes of Inherited Increased Susceptibility to Breast Cancer. Semin. Oncol. 2016, 43, 528-535. [CrossRef]

5. Campos, F.A.B.; Rouleau, E.; Torrezan, G.T.; Carraro, D.M.; Casali da Rocha, J.C.; Mantovani, H.K.; da Silva, L.R.; de Toledo Osório, C.A.B.; Moraes Sanches, S.; Caputo, S.M.; et al. Genetic Landscape of Male Breast Cancer. Cancers 2021, 13, 3535. [CrossRef] [PubMed]

6. Sy, S.M.H.; Huen, M.S.Y.; Chen, J. PALB2 Is an Integral Component of the BRCA Complex Required for Homologous Recombination Repair. Proc. Natl. Acad. Sci. USA 2009, 106, 7155-7160. [CrossRef]

7. Reid, S.; Schindler, D.; Hanenberg, H.; Barker, K.; Hanks, S.; Kalb, R.; Neveling, K.; Kelly, P.; Seal, S.; Freund, M.; et al. Biallelic Mutations in PALB2 Cause Fanconi Anemia Subtype FA-N and Predispose to Childhood Cancer. Nat. Genet. 2007, 39, 162-164. [CrossRef]

8. Xia, B.; Dorsman, J.C.; Ameziane, N.; de Vries, Y.; Rooimans, M.A.; Sheng, Q.; Pals, G.; Errami, A.; Gluckman, E.; Llera, J.; et al. Fanconi Anemia Is Associated with a Defect in the BRCA2 Partner PALB2. Nat. Genet. 2007, 39, 159-161. [CrossRef] [PubMed]

9. Jones, S.; Hruban, R.H.; Kamiyama, M.; Borges, M.; Zhang, X.; Parsons, D.W.; Lin, J.C.-H.; Palmisano, E.; Brune, K.; Jaffee, E.M.; et al. Exomic Sequencing Identifies PALB2 as a Pancreatic Cancer Susceptibility Gene. Science 2009, 324, 217. [CrossRef]

10. Antoniou, A.C.; Casadei, S.; Heikkinen, T.; Barrowdale, D.; Pylkäs, K.; Roberts, J.; Lee, A.; Subramanian, D.; De Leeneer, K.; Fostira, F.; et al. Breast-Cancer Risk in Families with Mutations in PALB2. N. Engl. J. Med. 2014, 371, 497-506. [CrossRef]

11. Southey, M.C.; Goldgar, D.E.; Winqvist, R.; Pylkäs, K.; Couch, F.; Tischkowitz, M.; Foulkes, W.D.; Dennis, J.; Michailidou, K.; van Rensburg, E.J.; et al. PALB2, CHEK2 and ATM Rare Variants and Cancer Risk: Data from COGS. J. Med. Genet. 2016, 53, 800-811. [CrossRef] [PubMed]

12. Pakkanen, S.; Wahlfors, T.; Siltanen, S.; Patrikainen, M.; Matikainen, M.P.; Tammela, T.L.J.; Schleutker, J. PALB2 Variants in Hereditary and Unselected Finnish Prostate Cancer Cases. J. Negat. Results Biomed. 2009, 8, 12. [CrossRef]

13. Eeles, R.A.; Olama, A.A.A.; Benlloch, S.; Saunders, E.J.; Leongamornlert, D.A.; Tymrakiewicz, M.; Ghoussaini, M.; Luccarini, C.; Dennis, J.; Jugurnauth-Little, S.; et al. Identification of 23 New Prostate Cancer Susceptibility Loci Using the ICOGS Custom Genotyping Array. Nat. Genet. 2013, 45, 385-391. [CrossRef]

14. Yang, X.; Leslie, G.; Doroszuk, A.; Schneider, S.; Allen, J.; Decker, B.; Dunning, A.M.; Redman, J.; Scarth, J.; Plaskocinska, I.; et al. Cancer Risks Associated With Germline PALB2 Pathogenic Variants: An International Study of 524 Families. J. Clin. Oncol. 2020, 38, 674-685. [CrossRef]

15. Wokołorczyk, D.; Kluźniak, W.; Stempa, K.; Rusak, B.; Huzarski, T.; Gronwald, J.; Gliniewicz, K.; Kashyap, A.; Morawska, S.; Dębniak, T.; et al. PALB2 Mutations and Prostate Cancer Risk and Survival. Br. J. Cancer 2021, 125, 569-575. [CrossRef] [PubMed]

16. Erkko, H.; Xia, B.; Nikkilä, J.; Schleutker, J.; Syrjäkoski, K.; Mannermaa, A.; Kallioniemi, A.; Pylkäs, K.; Karppinen, S.-M.; Rapakko, K.; et al. A Recurrent Mutation in PALB2 in Finnish Cancer Families. Nature 2007, 446, 316-319. [CrossRef] 
17. Mateo, J.; Carreira, S.; Sandhu, S.; Miranda, S.; Mossop, H.; Perez-Lopez, R.; Nava Rodrigues, D.; Robinson, D.; Omlin, A.; Tunariu, N.; et al. DNA-Repair Defects and Olaparib in Metastatic Prostate Cancer. N. Engl. J. Med. 2015, 373, 1697-1708. [CrossRef]

18. Horak, P.; Weischenfeldt, J.; von Amsberg, G.; Beyer, B.; Schütte, A.; Uhrig, S.; Gieldon, L.; Klink, B.; Feuerbach, L.; Hübschmann, D.; et al. Response to Olaparib in a PALB2 Germline Mutated Prostate Cancer and Genetic Events Associated with Resistance. Cold Spring Harb. Mol. Case Stud. 2019, 5, a003657. [CrossRef]

19. Farmer, H.; McCabe, N.; Lord, C.J.; Tutt, A.N.J.; Johnson, D.A.; Richardson, T.B.; Santarosa, M.; Dillon, K.J.; Hickson, I.; Knights, C.; et al. Targeting the DNA Repair Defect in BRCA Mutant Cells as a Therapeutic Strategy. Nature 2005, 434, 917-921. [CrossRef]

20. Schaeffer, E.; Srinivas, S.; Antonarakis, E.S.; Armstrong, A.J.; Bekelman, J.E.; Cheng, H.; D'Amico, A.V.; Davis, B.J.; Desai, N.; Dorff, T.; et al. NCCN Guidelines Insights: Prostate Cancer, Version 1.2021. J. Natl. Compr. Cancer Netw. JNCCN 2021, 19, 134-143. [CrossRef]

21. Seong, M.-W.; Cho, S.I.; Kim, K.H.; Chung, I.Y.; Kang, E.; Lee, J.W.; Park, S.K.; Lee, M.H.; Choi, D.H.; Yom, C.K.; et al. A Multi-Institutional Study of the Prevalence of BRCA1 and BRCA2 Large Genomic Rearrangements in Familial Breast Cancer Patients. BMC Cancer 2014, 14, 645. [CrossRef]

22. Janatova, M.; Kleibl, Z.; Stribrna, J.; Panczak, A.; Vesela, K.; Zimovjanova, M.; Kleiblova, P.; Dundr, P.; Soukupova, J.; Pohlreich, P. The PALB2 Gene Is a Strong Candidate for Clinical Testing in BRCA1- and BRCA2-Negative Hereditary Breast Cancer. Cancer Epidemiol. Biomark. Prev. 2013, 22, 2323-2332. [CrossRef]

23. Yang, C.; Arnold, A.G.; Trottier, M.; Sonoda, Y.; Abu-Rustum, N.R.; Zivanovic, O.; Robson, M.E.; Stadler, Z.K.; Walsh, M.F.; Hyman, D.M.; et al. Characterization of a Novel Germline PALB2 Duplication in a Hereditary Breast and Ovarian Cancer Family. Breast Cancer Res. Treat. 2016, 160, 447-456. [CrossRef] [PubMed]

24. Richardson, M.E.; Chong, H.; Mu, W.; Conner, B.R.; Hsuan, V.; Willett, S.; Lam, S.; Tsai, P.; Pesaran, T.; Chamberlin, A.C.; et al. DNA Breakpoint Assay Reveals a Majority of Gross Duplications Occur in Tandem Reducing VUS Classifications in Breast Cancer Predisposition Genes. Genet. Med. 2019, 21, 683-693. [CrossRef]

25. Tischkowitz, M.; Balmaña, J.; Foulkes, W.D.; James, P.; Ngeow, J.; Schmutzler, R.; Voian, N.; Wick, M.J.; Stewart, D.R.; Pal, T. Management of Individuals with Germline Variants in PALB2: A Clinical Practice Resource of the American College of Medical Genetics and Genomics (ACMG). Genet. Med. 2021, 23, 1416-1423. [CrossRef]

26. Parenti, S.; Rabacchi, C.; Marino, M.; Tenedini, E.; Artuso, L.; Castellano, S.; Carretta, C.; Mallia, S.; Cortesi, L.; Toss, A.; et al. Characterization of New ATM Deletion Associated with Hereditary Breast Cancer. Genes 2021, 12, 136. [CrossRef]

27. Houdayer, C.; Caux-Moncoutier, V.; Krieger, S.; Barrois, M.; Bonnet, F.; Bourdon, V.; Bronner, M.; Buisson, M.; Coulet, F.; Gaildrat, P.; et al. Guidelines for Splicing Analysis in Molecular Diagnosis Derived from a Set of 327 Combined in Silico/in Vitro Studies on BRCA1 and BRCA2 Variants. Hum. Mutat. 2012, 33, 1228-1238. [CrossRef] 